\title{
EFFECT OF HYDROTHERMAL TREATMENT ON GRINDABILITY AND FUEL CHARACTERISTICS OF EMPTY FRUIT BUNCH DERIVED HYDROCHAR
}

\author{
Sirawasith Ruksathamcharoen ${ }^{1 *}$, Muhammad W. Ajiwibowo ${ }^{2}$, Teerapong Chuenyam ${ }^{1}$, Adi \\ Surjosatyo $^{2}$, Kunio Yoshikawa ${ }^{1}$ \\ ${ }^{1}$ Department of Transdisciplinary Science and Engineering, Tokyo Institute of Technology, 4259 \\ Nagatsuta-cho, Midori-ku, Yokohama, Kanagawa 226-8503, Japan \\ ${ }^{2}$ Department of Mechanical Engineering, Faculty of Engineering, Universitas Indonesia, Kampus UI \\ Depok, Depok 16424, Indonesia
}

(Received: May 2018 / Revised: June 2018 / Accepted: September 2018)

\begin{abstract}
Hydrothermal treatment (HTT) is recognized as one of the promising thermochemical pretreatments for biomass energy. It provides a low energy requirement and an elimination of predrying. Furthermore, a water washing method for the treated biomass is employed. One of the most promising biofuel candidates is empty fruit bunch (EFB) due to the large yearly production in Indonesia. In this study, the quality of hydrochars derived from EFB was assessed for its quality as a solid fuel. Raw EFB is thermochemically treated by employing HTT, and its characteristics in regard to grindability are studied. The study suggested that commercial-scale HTT produces a solid fuel with a high heating value (HHV) with a value similar to Indonesian coal. In addition, it has lower ash content than the parent biomass, which reduces the probability of slagging and fouling in boilers. Furthermore, the particle size distribution profile suggested better characteristics than the parent biomass and some types of coal.
\end{abstract}

Keywords: Biomass energy; Empty fruit bunch; Grindability; Hydrothermal treatment

\section{INTRODUCTION}

Sustainability in energy has been an important issue in recent years and has gained importance since the recent signing of the Paris agreement (Sansaniwal et al., 2017). Use of fossil fuels worldwide has contributed significantly to the increase of the earth's temperature (McGlade \& Ekins, 2015). The utilization of renewable energy sources and alternative technologies to meet the $2{ }^{\circ} \mathrm{C}$ target are urgently needed, and there have been various research and development efforts in regard to clean and sustainable energy production (Surjosatyo et al., 2017; Zaini et al., 2017; Darmawan et al., 2018).

Bioenergy derived from biomass fuels are seen as a promising alternative energy source (Darmawan et al., 2018). The life cycles of biomass fuels are proven to be better than those of fossil fuels, and energy from biomass leaves no carbon footprint, as the generated $\mathrm{CO}_{2}$ will be processed again by plants for photosynthesis. In addition, the use of biomass wastes for fuel could potentially solve the waste problem that exists in developing countries (Prawisudha et al., 2012).

One of the biggest contributors to the biomass waste produced in Indonesia is the palm oil industry. Indonesia produces around $80 \%$ of the world's demand for palm oil. In the year 2014,

*Corresponding author's email: rsirawasith@gmail.com, Tel. +8145-924-5507, Fax. +8145-924-5518

Permalink/DOI: https://doi.org/10.14716/ijtech.v9i6.2360 
palm mills in Indonesia produced as much as 33.5 million tons of waste biomass, and $22 \%$ of it is empty fruit bunches (EFB) that are left after the oil processing, which indicates a strong potential for waste biomass to be used as fuel.

The bulky and fibrous nature of EFB makes it hard to handle (Zaini et al., 2017), and in its untreated state, EFB has a minimal high heating value (HHV) of about $16 \mathrm{MJ} / \mathrm{kg}$ and low energy density due to the fibrous composition. Therefore, pre-treatment of EFB is necessary before combustion. Among the various pre-treatments for solid fuel production, hydrothermal treatment (HTT) with water washing is one of the most promising (Novianti et al., 2015). With this method, the biomass is treated by pressurized sub-critical water at a temperature of 150 to $350^{\circ} \mathrm{C}$ and a pressure of around $2 \mathrm{MPa}$ (Jin, 2014). The advantage of this particular treatment is the elimination of a pre-drying process.

The treated biomass, which is referred to as hydrochar, has significantly higher energy density and generally better quality. However, the main reactions present in the HTT involve some degradation and decomposition of the biomass (Prawisudha et al., 2012), which will cause volume and mass reduction as the volatile matter of the biomass decreases (He et al., 2013).

The possibility of co-combustion of the produced hydrochar with coal in commercial boilers is one of the main interests in this research topic (Liu et al., 2012). In this regard, the milling process of solid fuels for pulverized solid fuel boilers is also a matter of significance (Bridgeman et al., 2010). The particle size distribution of the fuel affects important characteristics such as combustion efficiency, the amount of unburned carbon in the ash, and combustion stability (Sarroza et al., 2017). In addition, the operation of the pulverizing unit is critical for the successful reduction of $\mathrm{NO}_{\mathrm{x}}$ emissions in boilers. A typical pulverization process includes drying, grinding, classification (sizing), and selection of a system for feeding the fuel to the burner. Each of these stages is influenced by the physical properties and quality of the fuel.

The most common grindability test for coals is the Hardgrove grindability index (HGI), which was chosen for this study to investigate the grindability of the hydrochar. This method is used to predict the capabilities, performance, and energy requirements of the mill as well as the typical particle size distribution after milling. This is regarded as an important parameter for fuel quality and is used in coal contract specification. The test, as described in the British Standard 1016-112:1995, involves grinding $50 \mathrm{~g}$ of air-dried coal with a fixed particle size distribution between $600 \mu \mathrm{m}$ and $1.18 \mathrm{~mm}$ for 60 revolutions in a machine designed for Hardgrove grindability testing. The ground samples are then sieved through a $75 \mu \mathrm{m}$ sieve.

For this study, first, the calibration graph was plotted using four standard reference sample coals with known HGI values. Once this graph was obtained, the proportion of the sample material passing through the $75 \mu \mathrm{m}$ sieve was measured and plotted on the calibration curve, from which the HGI was determined. Generally, higher HGI values mean that the fuel is easier to grind, so it has lower grinding power requirements and produces a higher output of fuel in the mill and through to the boiler.

This paper explains the upgrading capability of HTT and subsequent water washing of the hydrochars in regard to the grindability and quality of the product as a solid fuel. Also presented are the proximate and ultimate analyses along with the grindability study, and the results indicated that a high-quality solid fuel comparable to coal was obtained. 


\section{METHODS}

\subsection{HTT and Water Washing Process}

Figure 1a shows a commercial-scale HTT plant in South Tangerang, Indonesia, which was utilized for this study. The plant consists of a $10 \mathrm{~m}^{3}$ reactor equipped with a stirrer and a boiler that feeds saturated steam into the reactor. The simplified process flow diagram is shown in Figure $1 b$.

The raw EFB is supplied to the reactor along with saturated steam from the boiler at a temperature between $150^{\circ} \mathrm{C}$ and $180^{\circ} \mathrm{C}$ and a pressure of $2 \mathrm{MPa}$. These conditions are kept for 30 minutes while, inside the reactor, the biomass is broken down. Afterward, a sludge-like product is ejected from the reactor and then water washed to remove chlorine and potassium content. Finally, the sludge is naturally air-dried.

The washing experiment was conducted by adapting a washing machine for the purpose. Room temperature water and $20 \mathrm{~kg}$ of commercial-scale hydrothermally treated EFB (HTT-EFB) were fed into the adapted washing machine and held for $30 \mathrm{mins}$ and then the commercial-scale washed HTT-EFB was discharged and naturally air-dried for a day. Then, the products were shipped to Tokyo Institute of Technology for further testing and analysis.

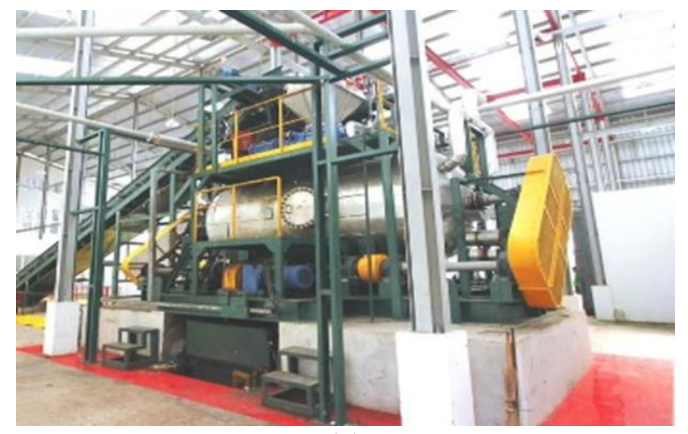

(a)

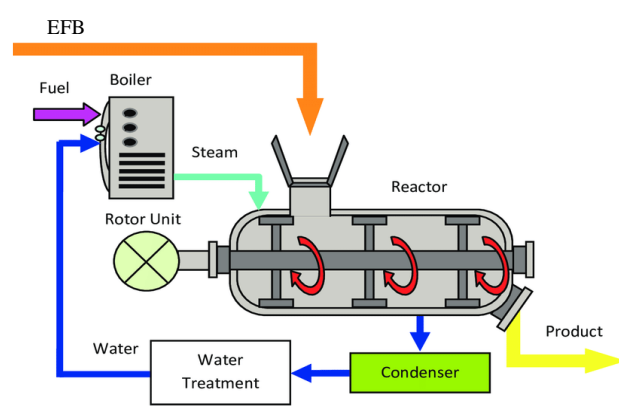

(b)

Figure 1 (a) Commercial-scale HTT plant in South Tangerang, Indonesia; (b) simplified process flow diagram of the plant

\subsection{Fuel Characteristics}

\subsubsection{Fuel samples}

Four coal samples with known HGI values were supplied by and supported from the Central Research Institute of Electric Power Industry (CRIEPI) in Japan. The coal samples were received with particle sizes greater than $6 \mathrm{~mm}$ in diameter. The coals were dried in the oven at a temperature of $105^{\circ} \mathrm{C}$ for $24 \mathrm{~h}$ and then placed in a sealed plastic bottle. The hydrochars were obtained from the commercial HTT plant in Indonesia, and the EFB was of Thai origin.

\subsubsection{Analytical method}

To investigate the quality of the fuel, ultimate and proximate analyses were employed. The determination of the elements of the samples was performed with a vario MICRO cube elemental analyzer (Elementar Analysensysteme $\mathrm{GmbH}$, Langenselbold, Germany), while the investigation of fixed carbon content, volatile matters, and ash content of the raw and washed hydrochar products was conducted using proximate analysis. All the analyses were carried out on both the raw material and on the hydrothermally treated products. Proximate analysis was performed using a SHIMADZU D50 simultaneous TGA/DTA analyzer based on ASTM D 3172, and Dulong's formula was used to determine the HHV.

$$
\mathrm{HHV}=0.3491 \mathrm{C}+1.1783 \mathrm{H}+0.1005 \mathrm{~S}-0.1034 \mathrm{O}-0.0151 \mathrm{~N}-0.0211 \mathrm{Ash}
$$




\subsection{Grindability Test}

For this study, a modified volumetric HGI test was utilized that was adopted from previous research (He et al., 2013; Jin, 2014). For the modified HGI test, a planetary ball mill (Mono Mill PULVERISETTE 6 classic line, FRITSCH, Pittsboro, NC, USA) was employed.

\subsubsection{Calibration of the ball mill}

First, the planetary ball mill (Mono Mill PULVERISETTE 6 classic line, FRITSCH, Pittsboro, NC, USA) is calibrated by using four coal samples with known HGI values, where the steps were as follows:

1. Approximately $1 \mathrm{~kg}$ of standard reference coal with a known HGI was crushed using a laboratory cutting mill.

2. The specimens were then sieved using $1180 \mu \mathrm{m}$ and $600 \mu \mathrm{m}$ sieve opening sizes on a sieve shaker.

3. $50 \mathrm{~cm}^{3}$ of each sample was measured out and weighed using a $250 \mathrm{~cm}^{3}$ plastic measuring cylinder with an accuracy of $\pm 0.1 \mathrm{~cm}^{3}$ and a balance accurate to $\pm 0.01 \mathrm{~g}$.

4. The $50 \mathrm{~cm}^{3}$ of sample was manually loaded into a $420 \mathrm{ml}$ capacity stainless steel milling cup with $20 \times 20 \mathrm{~mm}$ diameter stainless steel balls and then ground for $2 \mathrm{~min}$ at $170 \mathrm{rpm}$.

5. The samples were taken out of the steel milling cup and separated using a $75 \mu \mathrm{m}$ sieve and shake on a horizontal sieve shaker for $5 \mathrm{~min}$. The resulting two fractions were weighed to the nearest $0.01 \mathrm{~g}$. If there was a loss of sample greater than $0.5 \mathrm{~g}$, the test was aborted and repeated.

6. The mass, in grams, passing through the $75 \mu \mathrm{m}$ sieve was calculated using Equation 2,

$$
m=\left(m_{v}-m_{i}\right) / m_{v}
$$

where $m$ is the percentage of sample that passed through the $75 \mu \mathrm{m}$ sieve, $m_{v}$ is the mass of $50 \mathrm{~cm}^{3}$ of sample, and $m_{i}$ is the mass of sample retained with the $75 \mu \mathrm{m}$ sieve.

As mentioned in the previous section, four coal samples with known HGI values were used for comparison and calibration. Each test of the samples was repeated three times, and the mean value was calculated. These steps were repeated for all four coals, and the results were used to plot a calibration curve for the mill of HGI versus $\mathrm{m}$. By employing the least square method, an equation for the linear fit of the data from the standard reference coal was acquired.

The linear equation for the sum of least squares is expressed as shown in Equation 3.

$$
Y=a+b X
$$

where $Y$ is the HGI, $a$ is the y-axis intercept point, $b$ is the slope of the regression line, and $X$ is the percentage of sample mass that passed through the $75 \mu \mathrm{m}$ sieve.

The same calibration method was also conducted for the treated and untreated EFB, following steps 1 through 6 for each feedstock and then repeated three times. Afterward, the average values of the results were calculated and plotted on the calibration curve. The HGI value of biomass and water-washed hydrothermally treated EFB can be determined by plotting on the graph and substituting the linear equation that was obtained from the mill calibration.

Additionally, the obtained $m$ values will later be used to calculate and assign equivalent HGI values after pulverizing the feedstocks and biomass, using Equation 4.

$$
H I_{\text {equiv }}=(m-12.644) / 6.5
$$


A correlation of the Bond Work Index $\left(\mathrm{W}_{\mathrm{i}}\right)$ and HGI based on McIntyre and Plitt's theory (1980) was employed to calculate a comparative study.

$$
\begin{aligned}
W i_{a} & =1622 / H G I 1.08 \\
W i_{b} & =2017 / H G I 1.02
\end{aligned}
$$

On the other hand, Williams et al. (2015) carried out experiments to find the correlation between $\mathrm{W}_{\mathrm{i}}$ and HGI based on untreated and treated biomass pellets. This correlation $\left(\mathrm{Wi}_{\mathrm{b}}\right)$ was adopted for the comparative study between the two equations, and these correlations were used to determine the energy requirement for crushing these fuels.

\subsubsection{Particle size distribution profile}

To provide a more precise assessment of the pulverization behavior of the thermally pre-treated fuel in comparison to coal, a particle size distribution study of the ground fuels was also conducted utilizing the same grinding process described in steps 1 through 4 above. However, after that process, the fuels were sieved in a series of sieves with mesh sizes of $600 \mu \mathrm{m}$, $355 \mu \mathrm{m}, 212 \mu \mathrm{m}, 150 \mu \mathrm{m}, 75 \mu \mathrm{m}$, and $53 \mu \mathrm{m}$. The mass of sample collected on each sieve was weighed and calculated as a cumulative percentage of the original sample mass. Finally, the particle size distribution of raw and treated biomass was plotted alongside the reference coals to compare their grindability behavior.

\section{RESULTS AND DISCUSSION}

3.1. Ultimate and Proximate Analysis of EFB, Washed Hydrochars and Indonesian Coal The results of the proximate and ultimate analyses are shown in Table 1. The HTT primarily consisted of dehydration, condensation, and decarboxylation reactions that promoted the loss of carbon, hydrogen, and oxygen.

Table 1 Ultimate and proximate analysis results for untreated EFB (RAW-EFB), commercial-scale hydrothermally treated and water-washed EFB (HTT-EFB) and

\begin{tabular}{|c|c|c|c|}
\hline \multirow{2}{*}{ Chemical Composition } & \multicolumn{3}{|c|}{ Samples } \\
\hline & RAW-EFB & HTT-EFB & INDO-COAL \\
\hline \multicolumn{4}{|l|}{ Elemental Analysis (wt.\%) ${ }^{a}$} \\
\hline Carbon & 45.25 & 55.41 & 61.38 \\
\hline Hydrogen & 5.82 & 6.30 & 4.74 \\
\hline Nitrogen & 0.91 & 0.72 & 0.95 \\
\hline Sulfur & 0.27 & 0.55 & 0.30 \\
\hline Chlorine & 0.35 & 0.22 & 0.05 \\
\hline Oxygen $^{\mathrm{b}}$ & 43.00 & 33.60 & 28.48 \\
\hline \multicolumn{4}{|l|}{ Proximate Analysis (wt.\%) } \\
\hline Volatile Matter & 81.57 & 77.30 & 53.59 \\
\hline Fixed Carbon & 14.05 & 19.50 & 42.31 \\
\hline Ash & 4.40 & 3.20 & 4.10 \\
\hline $\mathrm{HHV}\left(\mathrm{MJ} \mathrm{kg-}^{1}\right)$ & 18.00 & 23.24 & 23.94 \\
\hline
\end{tabular}
Indonesian coal (INDO-COAL)

For thermochemical treatment and for fuel in general, oxygen loss is the most important and most desirable factor because it directly increases the energy value (Hoekman et al., 2011). Previous research has reported that an increase of reaction temperature affects the degradation 
of hydrogen and oxygen content in the biomass significantly (He et al., 2013; Parshetti et al., 2013; Novianti et al., 2015). The result for the HTT combined with the washing process (HTTEFB) showed that the carbon content of the solid products was significantly increased (46.73\%) and is considerably higher than the raw material (RAW-EFB). Xu et al. (2013) found that carbon content in hydrochar is not only dependent on operating temperature but also on the carbon content of the original feedstocks. With regard to oxygen content, the HTT-EFB washed hydrochar showed an obvious crucial degradation from $43 \%$ in the RAW-EFB to $33.60 \%$ in the treated material. Kambo and Dutta (2014) reported that the precipitation of carbon compounds in the porous structure of hydrochar would increase the overall HHV (carbon content). Thus, the HTT clearly increased the energy content of the products.

The energy content of the starting dry feedstock was $18 \mathrm{MJ} / \mathrm{kg}$, and the energy content of the HTT-EFB was considerably similar to the energy content of Indonesian coal $(23.94 \mathrm{MJ} / \mathrm{kg})$, which is classified as lignite. The chlorine content of the RAW-EFB was around $0.7 \%$, which could contribute to corrosion problems in thermochemical conversion systems or combustion boilers as well as contributing to acid gas formation (Arias et al., 2008; Chew \& Doshi, 2011). Table 1 shows that an approximate 37\% reduction of chlorine was observed after employing HTT and washing, leading to a better fuel property for combustion as it can lower the fouling and slagging tendency in furnaces (Arias et al., 2008). Because chlorine is commonly found in the form of the monovalent ion chloride $(\mathrm{Cl}-)$, which is loosely bound to the exchange site and in low quantities as organic compounds (Novianti et al., 2015), it could be easily removed during HTT and the washing process. Previous work has also suggested that by washing, the ionic form of chlorine could be easily removed (Harsono et al., 2016; Novianti, 2016). Furthermore, the reduction of volatile matter that was observed in the HTT products was nearly compensated for by the increase of fixed carbon (He et al., 2013).

By employing a combination of pre-treatments (HTT and water washing), volatile matter in the HTT-EFB was reduced to around $4.2 \%$, and fixed carbon increased $39 \%$ from RAW-EFB biomass, meaning the effects of the HTT were in agreement with previous studies (He et al., 2013; Novianti et al., 2014). The increase in fixed carbon content was credited to the devolatilization of volatile matter and the mass conversion during HTT. Some research has found that the volatile matter loss was higher than the increase in fixed carbon, indicating that the volatile matter was also transformed into other products such as $\mathrm{CO}_{2}$ or other liquid substances (Berge et al., 2011; Kang et al., 2012).

The fraction of volatiles in combustible carbon (volatile matter [volatile matter + fixed carbon]) shows that the value of HTW-EFB washed hydrochars (0.79) was similar to hydrothermally treated EFB at $200^{\circ} \mathrm{C}$ for $30 \mathrm{~min}(0.77)$ in a previous study that utilized a lab-scale autoclave (Novianti et al., 2014). The disadvantage of high volatile matter content was a reduction in combustion efficiency and an increase in emissions (Liu \& Han, 2015). Moreover, a lower fraction of volatiles in combustible carbon can minimize the differences between washed hydrochar and conventional coal, which leads to better co-combustion potential without modification to the furnaces.

The hydrochar is also observed to have lower amounts of ash compared to RAW-EFB, which ranges from $2 \%$ to $3.2 \%$ (Table 1), and the percentage of ash content was significantly diminished after employing HTT. The inorganic material in the form of loose dirt from the biomass processing was removed in the HTT process, leading to the decrease of the ash content (3). Further, in more severe HTT conditions, the inorganic solubilization from EFB is increased, which tends to enhance the solubilization and removal rate of inorganic compounds (Lynam et al., 2011). By combining HTT with a water washing process, inorganic constituents such as chlorine could be further reduced in the treated products. HTT accompanied with water 
washing significantly increased the ash removal rate (mostly potassium content) in raw biomass and hydrothermally treated EFB (Novianti et al., 2015), which promotes less slagging and fouling in combustion boilers. The mechanism of water washing is effective because the inorganic materials that are abundantly present in biomass and hydrochars are in water-soluble form, making them easy to remove.

\subsection{Grindability Test Results}

\subsubsection{HGI results}

The four HGI standard reference coals were successfully ground in the mill using the conditions explained in Section 2.3.1. The results and the calibration graph for the four coals with HGI values of 36.8, 47, 56 and 95.7 are shown in Figure 2. The $\mathrm{R}^{2}$ value for the correlation was 0.98 .

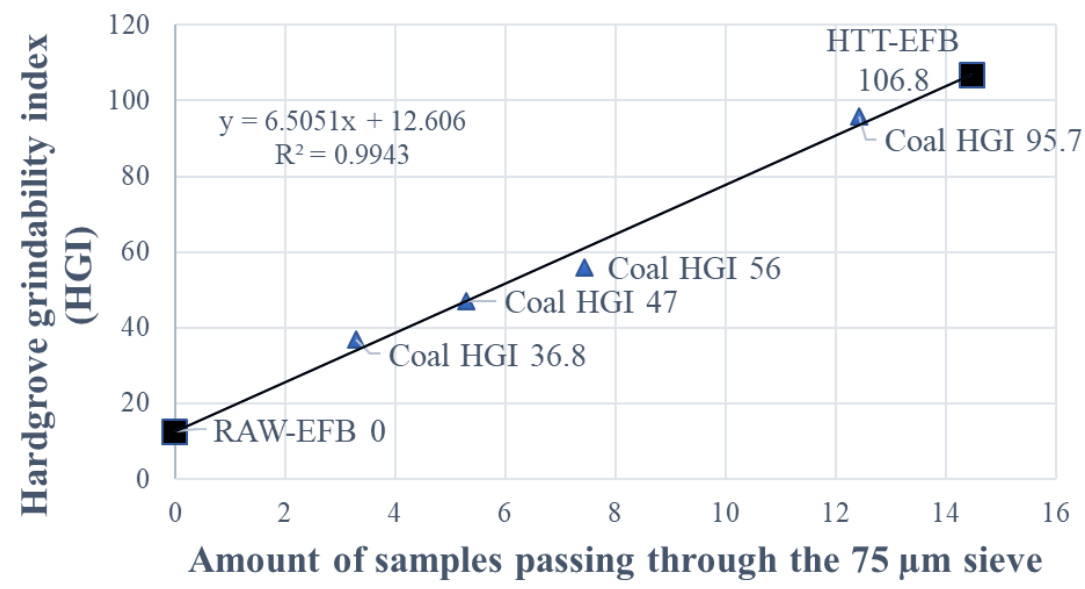

$(\%)$

Figure 2 Calibration and results graph from four standard reference coals using the PULVERISETTE 6 ball mill

While this method appeared to be successful in determining the changes in grindability of the treated EFB, it also has some limitations because the correlation was not based on biomass characteristic, which was classified as ductile material based on the stress-strain graph in the previous section.

Table 2 Calculated theoretical HGI values of biomass fuels (from calibration curve)

\begin{tabular}{lrrrc}
\hline \multicolumn{1}{c}{ Samples } & $\mathrm{m}(\%)$ & HGI & $\begin{array}{c}\mathrm{W}_{\mathrm{i}}^{\mathrm{a}} \\
(\mathrm{Kw} \mathrm{h} / \text { ton })\end{array}$ & $\begin{array}{c}\mathrm{W}_{\mathrm{i}}^{\mathrm{b}} \\
(\mathrm{Kw} \mathrm{h} / \text { ton })\end{array}$ \\
\hline Coal HGI 95.7 & 12.43 & 95.7 & 11.77 & - \\
Coal HGI 56 & 7.43 & 56.00 & 20.99 & - \\
Coal HGI 47 & 5.29 & 47.00 & 25.36 & - \\
Coal HGI 36.8 & 3.30 & 36.80 & 33.03 & - \\
HTT-EFB & 14.48 & 106.80 & 10.45 & 17.20 \\
RAW-EFB & 0.00 & 12.60 & 104.72 & 151.63 \\
\hline
\end{tabular}

However, the HGI values that were used in the equations were calculated using a traditional HGI procedure, while this study used a modified HGI procedure, which could cause some error in the data. Further, for some of the treated biomass, the amount of sample in this size range was less than $50 \%$ as most were ground to $<600 \mu \mathrm{m}$ in the preliminary milling stage. Therefore, the result may not represent the entire sample. 


\subsubsection{Particle size distribution}

The particle size distribution after pulverization was successfully assessed to gather the grindability behavior for each sample. The coals and EFB samples were analyzed to provide data on the particle size distribution of standard reference coals with known HGI values and treated samples. The data presented in Figure 3 shows that a larger proportion of finer particles are obtained from softer or structurally weaker coals.

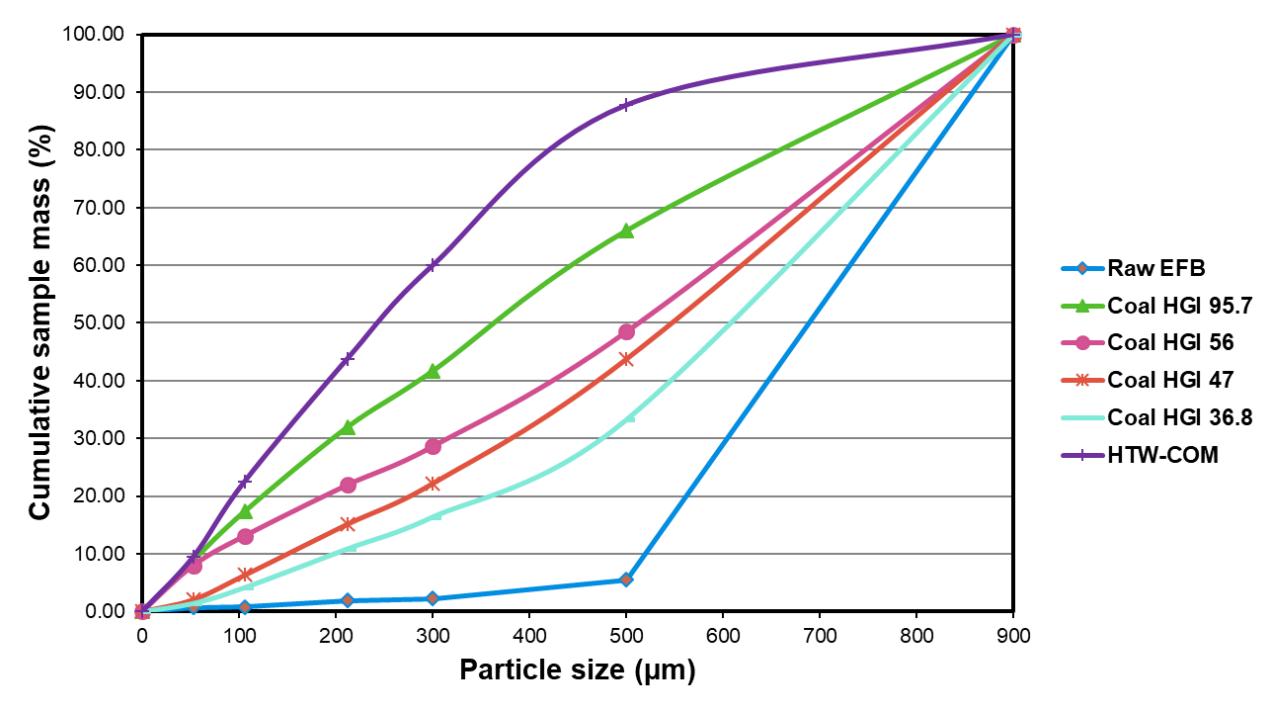

Figure 3 Particle distribution profile of the four reference coals, raw biomass and treated biomass after a grinding experiment

It can be observed that the HTT-EFB products showed a significant change in particle size distribution profiles. The particle size distribution of ground HTT-EFB with a calculated HGI value of 106.8 has a better profile than coal with an HGI of 95.7. Therefore, under the same grinding and processing conditions as coal samples, HTT-EFB should be easier to grind. Additionally, in the $0-500 \mu \mathrm{m}$ particle size range, the distribution graph of HTT-EFB shows the steepest curve among the samples, which indicates a large proportion of ground HTT-EFB particles were retained in the smallest particle size range. This is very beneficial for solid fuels as it would increase the combustion efficiency in commercial furnaces.

Furthermore, the particle distribution graph of untreated EFB reflects poor behavior when compared to the HTT-EFB graph. In the $0-500 \mu \mathrm{m}$ particle size range, the graph only shows a slight curve, which means only a small proportion of ground RAW-EFB biomass was gathered in these particle ranges. Moreover, when the range of particle size becomes larger than $500 \mu \mathrm{m}$, the particle distribution graph of RAW-EFB shows the steepest curve, which indicates that over $95 \%$ of the RAW-EFB particle sizes were equal to or greater than $500 \mu \mathrm{m}$. This behavior is due to the fact that the raw biomass is designated ductile material, which is extremely hard to crush into fine particle sizes in a standard ball mill.

\section{CONCLUSION}

An experimental study regarding the upgrading of EFB as a sustainable solid fuel was successfully carried out, and a thorough analysis was done to assess the characteristics of the thermochemically treated biomass as solid fuel. The results showed that the hydrochars produced from the HTT could potentially be a substitute for coal or, as in this case, it has the possibility of being co-combusted with coal without any significant modification to the boiler. It was found that commercial-scale hydrothermally treated and water-washed hydrochar from 
EFB had a higher HHV (23.269 MJ/Kg) which was equal to Indonesian coal (23.997 MJ/Kg), but it also came with higher sulfur content. Moreover, HTT offered lower ash content than Indonesian coal and lower chlorine content than raw EFB, which promotes less fouling of combustion boilers.

A modified HGI test was also successfully employed, and the grindability test further suggested that the hydrochar from HTT had significantly better HGI than the parent biomass. It was also found that the HGI value of the treated EFB was to some degree higher than the highest HGI for coal. Moreover, this method requires approximately 10 times less work than with the parent biomass, and the particle distribution profile was significantly improved by employing HTT. This indicates that HTT has a strong potential as a method to produce renewable solid fuel from biomass wastes, especially EFB. Furthermore, this research could also promote future works in the area of thermochemical treatments for producing sustainable solid fuels to potentially replace coal.

\section{REFERENCES}

Arias, B., Pevida, C., Fermoso, J., Plaza, M.G., Rubiera, F., Pis, J.J., 2008. Influence of Torrefaction on the Grindability and Reactivity of Woody Biomass. Fuel Processing Technology, Volume 89(2), pp. 169-175

Berge, N.D., Ro, K.S., Mao, J., Flora, J.R.V., Chappell, M.A., Bae, S., 2011. Hydrothermal Carbonization of Municipal Waste Streams. Environmental Science \& Technology, Volume 45(13), pp. 5696-5703

Bridgeman, T.G., Jones, J.M., Williams, A., Waldron, D.J., 2010. An Investigation of the Grindability of Two Torrefied Energy Crops. Fuel, Volume 89(12), pp. 3911-3918

Chew, J.J., Doshi, V., 2011. Recent Advances in Biomass Pretreatment - Torrefaction Fundamentals and Technology. Renewable and Sustainable Energy Reviews, Volume 15(8), pp. 4212-4222

Darmawan, A., Ajiwibowo, M.W., Yoshikawa, K., Aziz, M., Tokimatsu, K., 2018. Energyefficient Recovery of Black Liquor through Gasification and Syngas Chemical Looping. Applied Energy, Volume 219, pp. 290-298

Harsono, H., Putra, A.S., Maryana, R., Rizaluddin, A.T., H'ng, Y.Y., Nakagawa-izumi, A., Ohi, H., 2016. Preparation of Dissolving Pulp from Oil Palm Empty Fruit Bunch by Prehydrolysis Soda-Anthraquinone Cooking Method. Journal of Wood Science, Volume 62(1), pp. 65-73

He, C., Giannis, A., Wang, J.-Y., 2013. Conversion of Sewage Sludge to Clean Solid Fuel using Hydrothermal Carbonization: Hydrochar Fuel Characteristics and Combustion Behavior. Applied Energy, Volume 111, pp. 257-266

Hoekman, S.K., Broch, A., Robbins, C., 2011. Hydrothermal Carbonization (HTC) of Lignocellulosic Biomass. Energy \& Fuels, Volume 25(4), pp. 1802-1810

Jin, F., 2014. Application of Hydrothermal Reactions to Biomass Conversion. Springer-Verlag, Berlin, Heidelberg, Germany

Kambo, H.S., Dutta, A., 2014. Strength, Storage, and Combustion Characteristics of Densified Lignocellulosic Biomass Produced via Torrefaction and Hydrothermal Carbonization. Applied Energy, Volume 135, pp. 182-191

Kang, S., Li, X., Fan, J., Chang, J., 2012. Characterization of Hydrochars Produced by Hydrothermal Carbonization of Lignin, Cellulose, D-Xylose, and Wood Meal. Industrial \& Engineering Chemistry Research, Volume 51(26), pp. 9023-9031

Liu, Z., Han, G., 2015. Production of Solid Fuel Biochar from Waste Biomass by Low Temperature Pyrolysis. Fuel, Volume 158, pp. 159-165 
Liu, Z., Quek, A., Hoekman, S.K., Srinivasan, M.P., Balasubramanian, R., 2012. Thermogravimetric Investigation of Hydrochar-Lignite Co-combustion. Bioresource Technology, Volume 123, pp. 646-652

Lynam, J.G., Coronella, C.J., Yan, W., Reza, M.T., Vasquez, V.R., 2011. Acetic Acid and Lithium Chloride Effects on Hydrothermal Carbonization of Lignocellulosic Biomass. Bioresource Technology, Volume 102(10), pp. 6192-6199

McGlade, C., Ekins, P., 2015. The Geographical Distribution of Fossil Fuels Unused when Limiting Global Warming to $2^{\circ} \mathrm{C}$. Nature, Volume 517(7533), pp. 187-190

McIntyre, A., Plitt, L.R., 1980. The Interrelationship Between Bond and Hardgrove Grindabilities. CIM Bulletin, 73(818), pp. 149-155

Novianti, S., 2016. Low-potassium Content Pellet Fuel Production from Palm Empty Fruit Bunch by Hydrothermal and Washing Co-treatment. Doctoral Dissertation, Department of Environmental Science and Technology, Interdisciplinary Graduate School of Science and Engineering, Tokyo Institute of Technology, Tokyo, Japan

Novianti, S., Biddinika, M.K., Prawisudha, P., Yoshikawa, K., 2014. Upgrading of Palm Oil Empty Fruit Bunch Employing Hydrothermal Treatment in Lab-scale and Pilot Scale. Procedia Environmental Sciences, Volume 20, pp. 46-54

Novianti, S., Nurdiawati, A., Zaini, I.N., Prawisudha, P., Sumida, H., Yoshikawa, K., 2015. Low-potassium Fuel Production from Empty Fruit Bunches by Hydrothermal Treatment Processing and Water Leaching. Energy Procedia, Volume 75, pp. 584-589

Parshetti, G.K., Hoekman, S.K., Balasubramanian, R., 2013. Chemical, Structural and Combustion Characteristics of Carbonaceous Products Obtained by Hydrothermal Carbonization of Palm Empty Fruit Bunches. Bioresource Technology, Volume 135, pp. 683-689

Prawisudha, P., Namioka, T., Yoshikawa, K., 2012. Coal Alternative Fuel Production from Municipal Solid Wastes Employing Hydrothermal Treatment. Applied Energy, Volume 90(1), pp. 298-304

Sansaniwal, S.K., Pal, K., Rosen, M.A., Tyagi, S.K., 2017. Recent Advances in the Development of Biomass Gasification Technology: A Comprehensive Review. Renewable and Sustainable Energy Reviews, Volume 72, pp. 363-384

Sarroza, A.C., Bennet, T.D., Eastwick, C., Liu, H., 2017. Characterising Pulverised Fuel Ignition in a Visual Drop Tube Furnace by Use of a High-speed Imaging Technique. Fuel Processing Technology, Volume 157, pp. 1-11

Surjosatyo, A., Haq, I., Dafiqurrohman, H., Gibran, F.R., 2017. Effect of Rice Husk Ash Mass on Sustainability Pyrolysis Zone of Fixed Bed Downdraft Gasifier with Capacity of 10 kg/hour. AIP Conference Proceedings, Volume 1826, pp. 1-8

Williams, O., Eastwick, C., Kingman, S., Giddings, D., Lormor, S., Lester, E., 2015. Investigation into the Applicability of Bond Work Index (BWI) and Hardgrove Grindability Index (HGI) Tests for Several Biomasses Compared to Colombian La Loma Coal. Fuel, Volume 158, pp. 379-387

Xu, Q., Qian, Q., Quek, A., Ai, N., Zeng, G., Wang, J., 2013. Hydrothermal Carbonization of Macroalgae and the Effects of Experimental Parameters on the Properties of Hydrochars. ACS Sustainable Chemistry \& Engineering, Volume 1(9), pp. 1092-1101

Zaini, I.N., Novianti, S., Nurdiawati, A., Irhamna, A.R., Aziz, M., Yoshikawa, K., 2017. Investigation of the Physical Characteristics of Washed Hydrochar Pellets made from Empty Fruit Bunch. Fuel Processing Technology, Volume 160, pp. 109-120 